\title{
Association between pain outcomes and race and opioid treatment: Retrospective cohort study of Veterans
}

\author{
Diana J. Burgess, PhD; ${ }^{1-2 *}$ Amy A. Gravely, MA; ${ }^{1}$ David B. Nelson, PhD; ${ }^{1-2}$ Matthew J. Bair, MD, MS; ${ }^{3}$ Robert \\ D. Kerns, PhD; ${ }^{4}$ Diana M. Higgins, PhD; ${ }^{4}$ Melissa M. Farmer, PhD ${ }^{5}$ Melissa R. Partin, $\mathbf{P h D}{ }^{1-2}$ \\ ${ }^{1}$ Center for Chronic Disease Outcomes Research, Minneapolis Department of Veterans Affairs (VA) Health Care Sys- \\ tem, Minneapolis, MN; ${ }^{2}$ Department of Medicine, University of Minnesota Medical School, Minneapolis, MN; ${ }^{3}$ Center \\ for Health Information and Communication, VA Health Services Research \& Development, Richard L. Roudebush VA \\ Medical Center, Indianapolis, IN; Indiana University School of Medicine, Indianapolis, IN; and Regenstrief Institute Inc, \\ Indianapolis, IN; ${ }^{4}$ VA Connecticut Healthcare System, West Haven, CT; and Yale School of Medicine, New Haven, CT; \\ ${ }^{5}$ VA Health Services Research and Development Service, Center for the Study of Healthcare Innovation, Implementation \\ and Policy, VA Greater Los Angeles Healthcare System, Sepulveda, CA
}

\begin{abstract}
We examined whether pain outcomes (pain interference, perceived pain treatment effectiveness) vary by race and then whether opioid use moderates these associations. These analyses are part of a retrospective cohort study among 3,505 black and 46,203 non-Hispanic, white Department of Veterans Affairs (VA) patients with diagnoses of chronic musculoskeletal pain who responded to the 2007 VA Survey of Healthcare Experiences of Patients (SHEP). We used electronic medical record data to identify prescriptions for pharmacologic pain treatments in the year after diagnosis (Pain Diagnosis index visit) and before the SHEP index visit (the visit that made one eligible to complete the SHEP); pain outcomes came from the SHEP. We found no significant associations between race and pain interference or perceived effectiveness of pain treatment. VA patients with opioid prescriptions between the Pain Diagnosis index visit and the SHEP index visit reported greater pain interference on the SHEP than those without opioid prescriptions during that period. Opioid prescriptions were not associated with perceived treatment effectiveness for most patients. Findings raise questions about benefits of opioids for musculoskeletal pain and point to the need for alternative treatments for addressing chronic noncancer pain.
\end{abstract}

Key words: blacks, chronic pain, Department of Veterans Affairs, disparities, opioids, pain outcomes, pain treatment effectiveness, race, survey, Veterans.

\section{INTRODUCTION}

Numerous studies have shown that blacks are less likely than whites to be prescribed opioid analgesics for a variety of pain conditions [1]. These disparities have been viewed as especially problematic in light of evidence that blacks experience chronic pain that is more severe and more disabling than whites [2-7]. Although many factors contribute to these racial disparities in pain outcomes (e.g., racial differences in patients' beliefs about pain $[4,8-10]$, exposure to racial discrimination [11-12]), there is concern about the role of undertreatment

Abbreviations: $\mathrm{CI}=$ confidence interval, $\mathrm{HSR} \& \mathrm{D}=$ Health Services Research and Development Service, ICD-9 = International Classification of Diseases-9th Revision, NPCD = National Patient Care Database, OR $=$ odds ratio, PTSD = posttraumatic stress disorder, SHEP = Survey of Healthcare Experiences of Patients, VA = Department of Veterans Affairs.

*Address all correspondence to Diana J. Burgess, PhD; Center for Chronic Disease Outcomes Research, Minneapolis VA Health Care System, One Veterans Dr, Minneapolis, MN 55419. Email: Diana.Burgess@va.gov

http://dx.doi.org/10.1682/JRRD.2014.10.0252 
of pain [1-3,13]. Consequently, recent position papers have highlighted the importance of reducing racial disparities in opioid prescription and proposed strategies to accomplish this goal [2-3].

There is a tension, however, between the imperative to address racial disparities in opioid treatment and acknowledgment of the public health crisis caused by increased prescription of opioids, particularly in light of incomplete evidence about their benefits relative to the known risks. There are limited data on the long-term effectiveness and safety of opioids for the treatment of chronic noncancer pain [14-15] and mounting evidence of serious risks associated with opioids [15-18]. Although there have been numerous studies documenting racial disparities in opioid use [1], there is scant research on whether these disparities are, in fact, associated with poorer pain outcomes for black patients.

Our prior research found that among Department of Veterans Affairs (VA) patients diagnosed with a chronic musculoskeletal condition who reported moderate or high levels of pain and who were under age 65, blacks were less likely to be prescribed opioids than their white counterparts [19]. The objectives of this study were to examine whether pain outcomes (pain interference, perceived pain treatment effectiveness) among those who reported being treated for chronic pain at VA vary by race and then whether receipt of opioid prescriptions moderates these relationships.

\section{METHODS}

\section{Study Design}

This was a retrospective cohort study using survey data from the 2007 VA Survey of Healthcare Experiences of Patients (SHEP) ambulatory care module and data extracted from the VA National Patient Care Database (NPCD). This study was approved by the institutional review board of the Minneapolis VA Health Care System.

\section{Setting and Participants}

We identified a retrospective cohort using the 2007 SHEP ambulatory care module, a national survey administered quarterly by the VA Office of Quality and Performance, to solicit patient-reported information concerning recent specific episodes of outpatient care. Each individual selected was surveyed about an episode of care (referred to as the SHEP index visit). This survey was mailed to patients early in the second calendar month following their SHEP index visit, and data collection was closed 4 wk after the survey was mailed. We identified a sample of patients with chronic pain $(9,831$ black and 71,471 white patients, referred to as the "chronic pain sample") using the same criteria as we used in our previous research examining racial differences in opioid prescriptions in VA [19] (Figure 1). The sample included non-Hispanic black or white established and new primary care patients who were selected to be in the 2007 SHEP (irrespective of whether or not they responded to the SHEP) and met the following inclusion criteria: (1) any diagnoses of back, neck, or joint pain in the year prior to the SHEP index visit; (2) no cancer diagnoses in the year prior to the SHEP index visit; and (3) no outpatient opioid prescription received in the 3 mo prior to the first pain diagnosis (Pain Diagnosis index visit). Our rationale for restricting the sample to patients who had no opioid prescription in the first 3 mo prior to the Pain Diagnosis index visit was to ensure that the opioid was prescribed for treatment of that particular pain episode rather than for a different reason. In analyses examining pain interference as an outcome, we included only those patients who responded to the SHEP (3,505 non-Hispanic blacks and 46,203 non-Hispanic whites). In our analyses examining perceived treatment effectiveness as an outcome, we further restricted our sample to those who reported on the SHEP that they were treated for chronic pain in the VA in the past year (1,622 non-Hispanic blacks and 13,758 non-Hispanic whites).

\section{Study Outcomes}

Pain interference was measured using the SHEP item: "During the past 4 weeks, how much did pain interfere with your normal work (including both work outside the home and housework)?” This item is drawn from the Bodily Pain subscale of the 36-Item Short Form Health Survey (SF-36) [20]. Consistent with prior research [2122], we dichotomized responses into two categories: (1) not at all/a little bit and (2) moderately/quite a bit/ extremely. We decided to dichotomize the pain interference scale in order to capture the construct of functional limitations due to pain, in which "not at all/a little bit" represents every day aches and pains, whereas "moderately/quite a bit/extremely" represents clinically actionable pain, requiring comprehensive assessment and treatment [23]. 
Chronic pain sample: People who were sent SHEP

(from Burgess et al. [19])
Chronic pain sample: People who responded to SHEP and reported that they had been treated for chronic pain in VA in past year
9,831 black and 71,471 white patients in SHEP cohort with diagnosis of back, neck, or joint pain in year prior to SHEP index visit and other inclusion criteria*

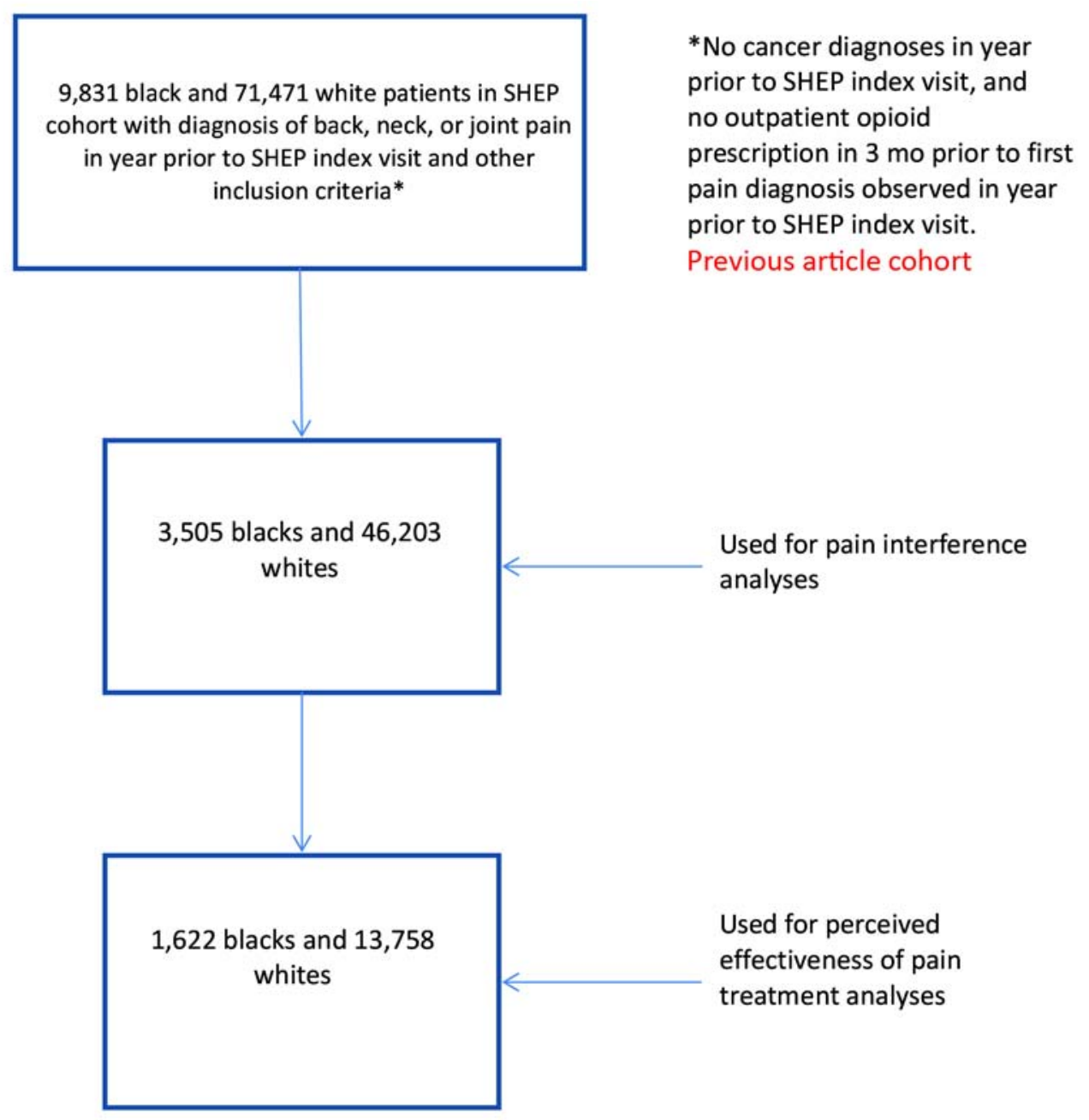

* No cancer diagnoses in year prior to SHEP index visit, and no outpatient opioid prescription in 3 mo prior to first pain diagnosis observed in year prior to SHEP index visit. Previous article cohort

\begin{abstract}
Chronic pain sample: People who responded to SHEP: SHEP responders
\end{abstract}

Figure 1.

Samples used to test specific hypotheses. SHEP = Survey of Healthcare Experiences of Patients, VA = Department of Veterans Affairs.

Perceived effectiveness of pain treatment among those who reported being treated for chronic pain in VA was measured using the SHEP item: "If you have been treated by a VA provider for chronic pain, please rate the effectiveness of your pain treatment.” This analysis only included those patients who reported on the SHEP that they were treated for chronic pain in the VA in the past year. Response options were poor, fair, good, very good, and excellent. Previous research with Veterans has demonstrated that single-item ratings of treatment effectiveness are significantly associated with posttreatment changes in self-reported ratings of pain severity, pain interference, and disability [24]. Responses were dichotomized into two categories: (1) poor and fair and (2) good, very good, and excellent. Consistent with prior research examining differences in perceived quality of care [25], we dichotomized the perceived effectiveness scale into "poor" and "fair" versus "good," "very good," and "excellent" in order to capture whether patients perceived their chronic pain treatment as ineffective versus effective.

\section{Primary Predictors}

Patient race was obtained from the SHEP (i.e., survey self-report) and supplemented with administrative data from the NPCD when missing. The SHEP race and ethnicity measures were used to derive two categories: non-Hispanic white and non-Hispanic black. 
Receipt of any opioid prescription was defined as an outpatient prescription of any opioid for any duration issued by a VA pharmacy between the Pain Diagnosis index visit and the SHEP index visit (Figure 2) obtained from the NPCD. The mean \pm standard deviation time period between the Pain Diagnosis index visit and the SHEP index visit was $163 \pm 134 \mathrm{~d}$.

\section{Demographic and Clinical Covariates}

Sex and age were obtained from the NPCD. Marital status was obtained from the SHEP and supplemented with NPCD data. We used the NPCD to obtain International Classification of Diseases-9th Revision (ICD-9) diagnostic codes from outpatient visits to determine whether patients had diagnoses of medical and mental health comorbidities, including prior pain-related diagnoses (i.e., neck, back, or joint pain); opioid use disorder; or other substance use disorder during the year prior to the first pain-related diagnosis using the same codes as were used in the TROUP (Trends and Risks of Opioid Use for Pain) Study [26]. ICD-9 codes were also used to identify
30 comorbidity measures developed by Elixhauser and colleagues for use with large administrative data sets [27]. Additional diagnoses (separate from Elixhauser measures) hypothesized to be associated with pain outcomes or pain treatment: phantom limb pain, psychogenic pain, spinal cord injury, and posttraumatic stress disorder (PTSD) were included in analyses (see Burgess et al. for diagnosis codes [19]).

VA guidelines recommend screening for the presence and intensity of pain at each outpatient visit using a numerical 0 (no pain) to 10 (worst pain imaginable) rating scale. In our analysis, we used the pain intensity rating that occurred at the Pain Diagnosis index visit if it was documented in the NPCD. If there was no documented pain intensity rating at the Pain Diagnosis index visit, we used the documented pain intensity rating at the most proximal time prior to the Pain Diagnosis index visit. We categorized pain intensity ratings using standard cutpoints indicating no pain (0), mild pain intensity (ratings of 1-3), moderate pain intensity (ratings of 4-6), and severe pain intensity (ratings of 7-10) [28-29].

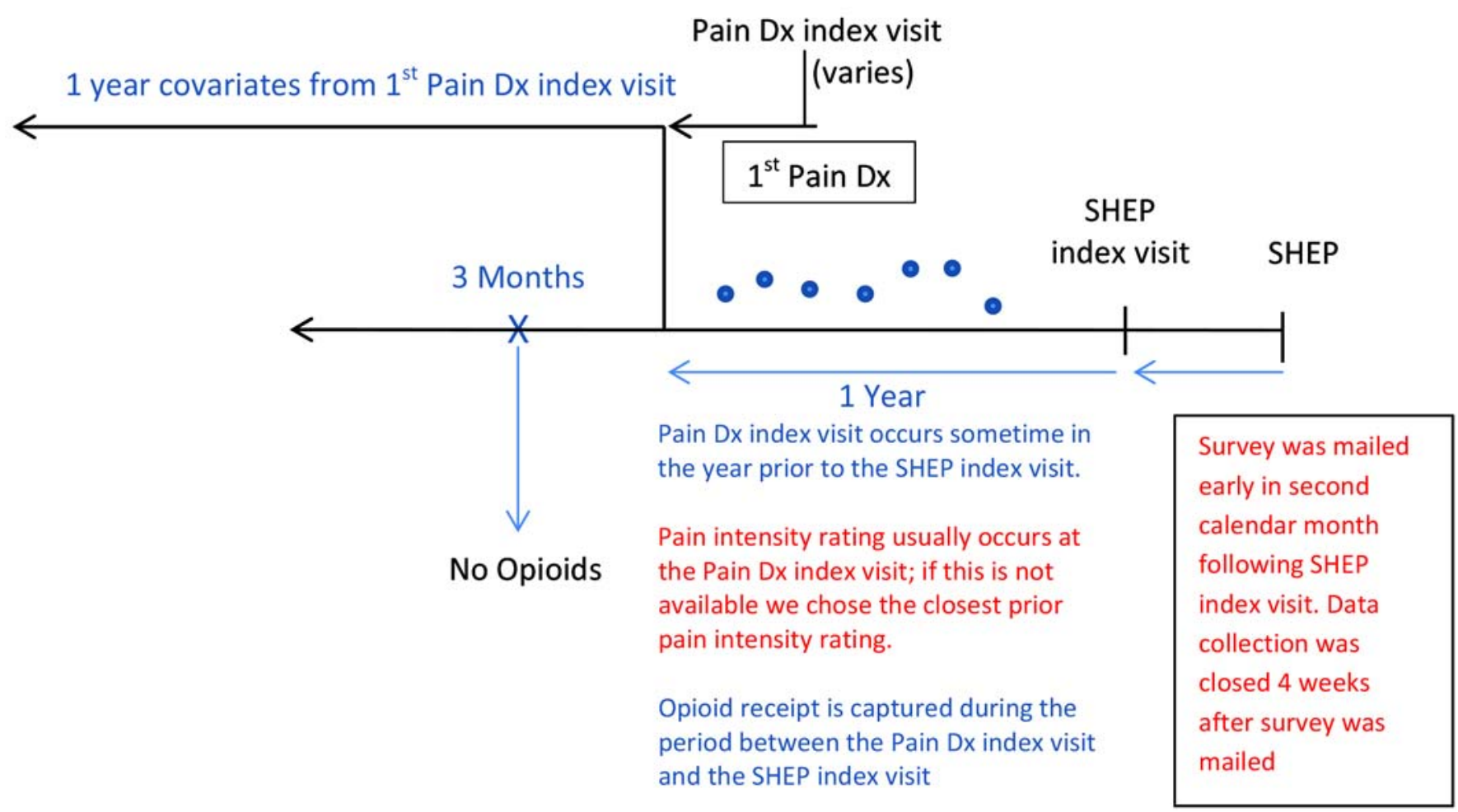

Figure 2.

Temporal structure of data. Dx = diagnosis, SHEP = Survey of Healthcare Experiences of Patients. 
Healthcare utilization in the year prior to the first pain diagnosis was summarized using the number of outpatient visits and inpatient admissions from NPCD data. We obtained information about whether the patient was classified as new to primary care versus established (i.e., previous primary care visit(s)) from the SHEP, as the likelihood of receiving an opioid may be greater among established patients.

\section{Statistical Analyses}

We fit a hierarchical logistic regression model for good to excellent effectiveness of pain treatment among the members of the cohort who responded to the perceived effectiveness SHEP item and who reported being treated for chronic pain at the VA within the past year. We investigated whether race was associated with the effectiveness of treatment and, subsequently, whether opioid use moderated any association between race and treatment effectiveness. As our analyses found that the likelihood of receiving opioids varied with prior pain intensity level, we stratified these analyses by prior pain intensity ratings. Within each subgroup (no, mild, moderate, and severe pain), we fit a generalized linear mixed logistic regression model incorporating fixed effects for race (black or white), new or established primary care patient, receipt of opioids between the Pain Diagnosis index visit and the SHEP index visit, days between the Pain Diagnosis index visit and the SHEP index visit, and an interaction between race and receipt of opioids combined with the demographic, utilization, prior pain diagnoses, and comorbidity measures discussed previously. Comorbidity measures were included as covariates if there was a 5 percent or greater difference in treatment rates among those with and without the comorbidity and at least 100 members of the cohort were diagnosed with the condition. The model incorporated (Gaussian) random intercepts for each facility and (Gaussian) random race effects for each facility to allow for race differences to vary by facility and also allow us examine overall race differences through the estimated fixed effects for race. These generalized linear mixed models were implemented using pseudo-likelihood algorithms in PROC GLIMMIX, SAS, version 9.2 (SAS Institute Inc; Cary, North Carolina).

The same process was used to investigate the association between race and perceived effectiveness of chronic pain treatment and whether opioid use moderated the association between race and perceived effectiveness. We conducted this analysis among the members of the cohort who responded to the perceived effectiveness SHEP item and who reported being treated for chronic pain at the VA within the past year.

Response to the SHEP was incomplete (61\% of our chronic pain sample responded to the SHEP). To assess the potential effect of survey nonresponse on the study findings, we fit a logistic regression for SHEP response using those demographic, medical and mental health comorbidities, and healthcare utilization measures that differed between responders and nonresponders as predictors. We estimated the propensity for responding to the SHEP from this model, formed eight strata from these estimated propensities, and verified that responders and nonresponders were well balanced within these strata. We then included this strata variable in the models (as an additional predictor) [30].

\section{RESULTS}

\section{Sample Characteristics by Race}

Black patients were more likely to be female and unmarried, more likely to have diagnoses of back and neck pain, and less likely to have a diagnosis of joint pain. Black patients were also more likely than white patients to have diagnoses of opioid use disorder, alcohol or drug use disorders, or a psychiatric disorder, including PTSD. (See Table 1 for tests of statistical significance.)

\section{Pain Interference}

Pain interference was not associated with race for any level of pain intensity rating (pain intensity rating 0 , $p=0.17 ; 1-3, p=0.54 ; 4-6, p=0.93$; and $7-10, p=$ 0.98). Opioid use did not moderate the association between race and pain interference for any level of pain (pain intensity rating $0, p=0.59 ; 1-3, p=0.41 ; 4-6, p=$ 0.51 ; and 7-10, $p=0.74$ ).

Pain interference was significantly higher for those who received an opioid prescription. The association between pain interference and opioid prescription was stronger for patients with lower pain intensity ratings: 0 (odds ratio $[\mathrm{OR}]=1.94,95 \%$ confidence interval $[\mathrm{CI}]=$ $1.71-2.19, p<0.001), 1-3$ (OR $=1.84,95 \% \mathrm{CI}=1.50$ 2.25, $p<0.001), 4-6(\mathrm{OR}=1.70,95 \% \mathrm{CI}=1.42-2.04, p<$ $0.001)$; and $7-10(\mathrm{OR}=1.45,95 \% \mathrm{CI}=1.21-1.75, p<$ 0.001). Table 2 presents observed and estimated prevalence ratings of pain interference for black and white patients who were and were not prescribed opioids, stratified by prior pain intensity ratings. 
JRRD, Volume 53, Number 1, 2016

Table 1.

Association between patient race and demographic, health-related, and utilization characteristics. Data presented as percentage or mean \pm standard deviation.

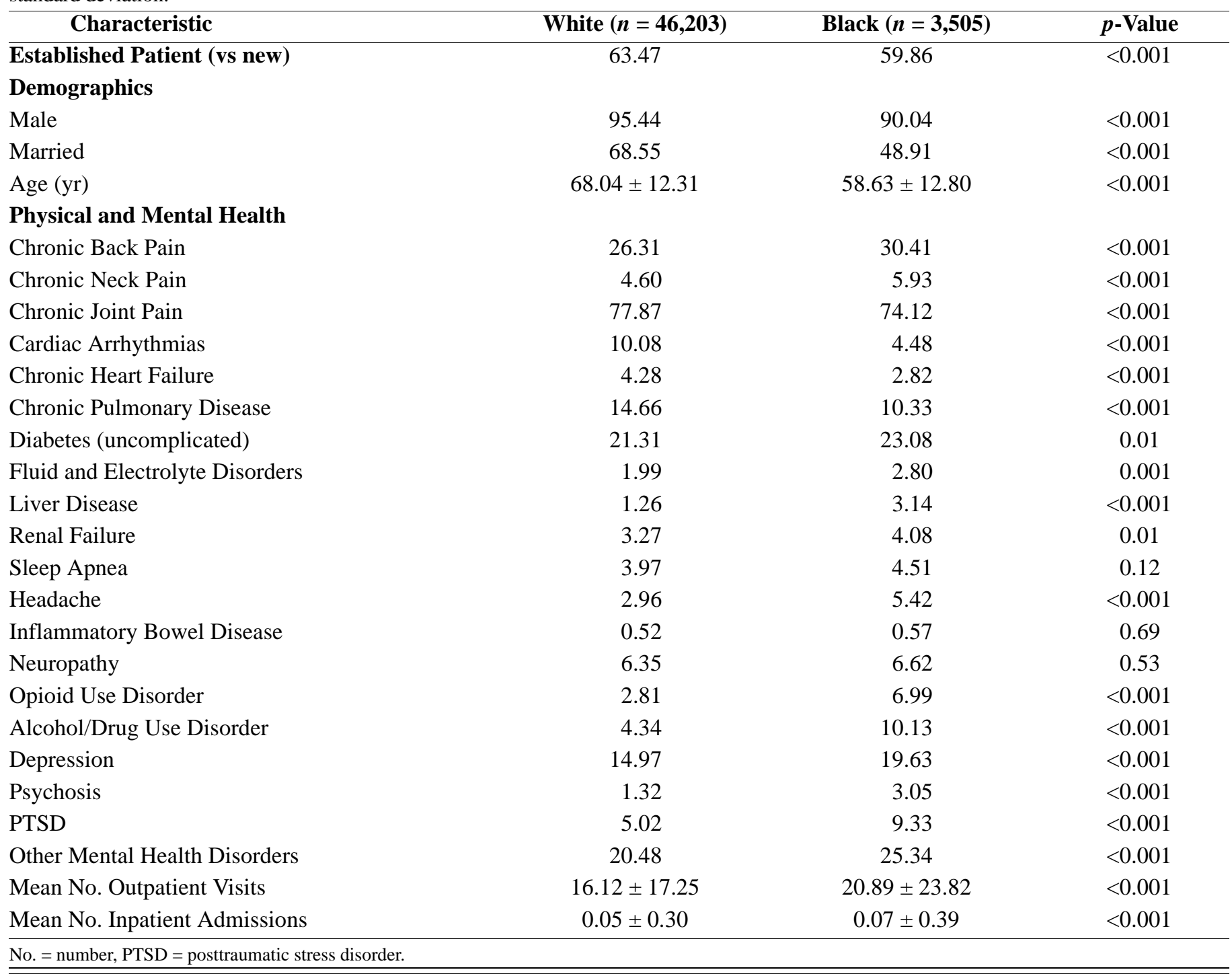

Table 2.

Observed and estimated prevalence ${ }^{*}$ of pain interference among black and white Veterans with and without opioid prescriptions.

\begin{tabular}{|c|c|c|c|c|c|c|c|c|c|c|c|c|}
\hline \multirow{3}{*}{$\begin{array}{l}\text { Prior Pain } \\
\text { Intensity } \\
\text { Score }\end{array}$} & \multicolumn{6}{|c|}{ Yes Opioids } & \multicolumn{6}{|c|}{ No Opioids } \\
\hline & \multicolumn{3}{|c|}{ Whites } & \multicolumn{3}{|c|}{ Blacks } & \multicolumn{3}{|c|}{ Whites } & \multicolumn{3}{|c|}{ Blacks } \\
\hline & Obs n (\%) & Est (\%) & $95 \% \mathrm{CI}$ & Obs n (\%) & Est (\%) & $95 \%$ CI & Obs $n(\%)$ & Est (\%) & $95 \% \mathrm{CI}$ & Obs $n(\%)$ & Est (\%) & $95 \% \mathrm{CI}$ \\
\hline 1-3, Mild & 702 (77.7) & 87.2 & $80.0-92.2$ & 38 (86.1) & 90.9 & $77.0-96.7$ & 6,352 (60.3) & 79.0 & 68.6-86.7 & 387 (63.0) & 78.1 & $67.1-86.2$ \\
\hline 4-6, Moderate & $1,137(84.0)$ & 91.0 & 85.5-95.0 & 114 (87.4) & 92.0 & 84.5-96.1 & 6,773 (72.0) & 86.0 & 78.0-91.4 & 615 (73.6) & 84.8 & 76.4-90.6 \\
\hline
\end{tabular}

Note: degrees of freedom $=46,407$.

${ }^{*}$ Calculated at typical facility with covariates (demographics, utilization, prior pain diagnoses, and comorbidities) at modal/mean values. $\mathrm{CI}=$ confidence interval, Est $=$ estimated, Obs = observed. 


\section{Perceived Effectiveness of Pain Treatment}

Perceived effectiveness of pain treatment was not associated with race (pain intensity rating $0, p=0.24$; $1-$ $3, p=0.06$; 4-6, $p=0.37$; and 7-10, $p=0.78$ ). Opioid use did not moderate the association between race and perceived effectiveness of pain treatment (pain intensity rating $0, p=0.71 ; 4-6, p=0.70$; and $7-10, p=0.15$ ), except among patients with mild pain intensity ratings $(1-3, p=0.008)$; however, this is difficult to interpret because of the small cell size of black patients in this category $(n=24)$. The main effect of opioid prescription was not significant, with the exception of the mild pain intensity group (pain intensity rating $0, p=0.13 ; 1-3, p=$ 0.003 ; $4-6, p=0.77$; and $7-10, p=0.37$ ). Table 3 presents observed and estimated prevalence ratings of perceived effectiveness of pain treatment for black and white patients who were and were not prescribed opioids.

\section{DISCUSSION}

Among VA primary care patients with a chronic noncancer pain diagnosis, race was not associated with pain interference or with perceived treatment effectiveness. Moreover, among black and white VA patients, receipt of an opioid prescription was significantly associated with greater pain interference and was not significantly associated with perceived treatment effectiveness, except for individuals with mild pain. The results do not vary significantly by age group. Hence, our prior findings of lower rates of opioid prescriptions among blacks than whites younger than $65 \mathrm{yr}$ did not appear to contribute to racial differences in pain outcomes [19].

To our knowledge, this is the only study to examine associations of racial disparities in opioid prescriptions on clinically relevant pain outcomes among chronic pain patients and one of the first to examine the effectiveness of opioid therapy in a large integrated healthcare system. Understanding the effect of racial disparities in opioid prescription is particularly important in light of mounting evidence of serious risks associated with opioids [15-18], the rapid increase in opioid prescription for chronic noncancer pain over the last 10-15 yr, and the lack of evidence on the long-term effectiveness and safety of opioids for this purpose [14-15].

Our findings raise the broader question of whether efforts to address racial disparities in pain should focus on reducing disparities in opioid prescription, as has been suggested in prior policy recommendations [3] —at least in the case of patients with chronic noncancer pain. The use of race in decisions to prescribe opioids is clearly inconsistent with good medical practice and arguably constitutes racial bias. Although our results should be considered preliminary because of our retrospective cohort study design, which precludes the ability to draw causal inferences about the effect of opioid prescription on pain outcomes, the high levels of pain interference among the majority of black and white patients with prior opioid prescriptions suggests that additional treatment modalities may be needed for patients with chronic noncancer pain. Indeed, there is growing consensus that chronic noncancer pain is best addressed by a biopsychosocial approach that acknowledges the role of psychological and environmental factors in pain [31], some of which differ by race and hence contribute to worse pain among blacks. For example, blacks experience greater painrelated fear and lower self-efficacy in coping with pain $[4,8-10]$. Blacks are more likely to reside in neighborhoods that make engaging in physical activity difficult [32-33]. Blacks are also more likely to be exposed to

Table 3.

Observed and estimated prevalence ${ }^{*}$ of perceived effectiveness of pain treatment among black and white Veterans with and without opioid prescriptions who reported being treated at Department of Veterans Affairs for chronic pain.

\begin{tabular}{|c|c|c|c|c|c|c|c|c|c|c|c|c|}
\hline \multirow{3}{*}{ Pain Intensity } & \multicolumn{6}{|c|}{ Yes Opioids } & \multicolumn{6}{|c|}{ No Opioids } \\
\hline & \multicolumn{3}{|c|}{ Whites } & \multicolumn{3}{|c|}{ Blacks } & \multicolumn{3}{|c|}{ Whites } & \multicolumn{3}{|c|}{ Blacks } \\
\hline & Obs n (\%) & Est (\%) & $95 \%$ CI & Obs n (\%) & Est (\%) & $95 \%$ CI & Obs $n(\%)$ & Est (\%) & $95 \%$ CI & Obs $n(\%)$ & Est (\%) & $95 \%$ CI \\
\hline 0, No Pain & 850 (62.7) & 56.7 & $43.3-69.2$ & 89 (58.1) & 53.9 & 38.0-69.0 & 4,396 (66.5) & 60.0 & $46.4-72.1$ & 488 (59.1) & 54.8 & $41.6-67.3$ \\
\hline 1-3, Mild & 439 (67.5) & 52.8 & $33.1-71.6$ & 24 (37.5) & 26.5 & $10.6-52.3$ & $1,850(62.4)$ & 41.1 & 23.2-61.6 & 161 (61.4) & 45.2 & $26.1-65.7$ \\
\hline 4-6, Moderate & 764 (55.9) & 62.4 & $47.1-75.6$ & $82(58.4)$ & 66.8 & 49.2-80.7 & 2,637 (56.4) & 62.1 & $46.3-75.6$ & $316(54.7)$ & 63.9 & $48.3-77.0$ \\
\hline 7-10, Severe & 917 (52.4) & 46.0 & $30.3-62.5$ & $126(56.5)$ & 51.3 & $33.9-68.4$ & 1,905 (53.2) & 45.2 & $29.1-62.4$ & 336 (47.9) & 42.0 & $26.6-58.6$ \\
\hline
\end{tabular}

Note: degrees of freedom $=15,307$.

${ }^{*}$ Calculated at typical facility with covariates (demographics, utilization, prior pain diagnoses, and comorbidities) at modal/mean values. $\mathrm{CI}=$ confidence interval, Est $=$ estimated, Obs $=$ observed. 
discrimination, which has been shown to contribute to a more severe pain experience [11].

It is notable that black and white patients did not significantly differ in their perceptions of chronic pain treatment effectiveness or in their reported pain interference in our adjusted analyses. At first glance, these results seem inconsistent with the large body of literature documenting racial disparities in pain care and treatment $[2,4]$. However, most of the literature describing racial disparities in treatment (including several studies conducted at the VA prior to the present study [20,34-37]) examines specific types of treatment (e.g., opioid therapy, pain-relieving surgical procedures) rather than patients' evaluations of their overall quality of pain treatment. An exception is Dobscha et al. who, using data from the 2005 SHEP, found that black men perceived their pain treatment to be less effective than white men, after controlling for demographics, pain, and mental health comorbidities [20]. It is unclear whether discrepancy between the present findings and those of Dobscha et al. are due to methodological differences between the two studies or the fact that our study used data collected at a later time point, in which pain care quality in VA could have conceivably improved.

There are a number of limitations to this study and remaining questions that require additional research to address. Because we examined only VA outpatients, these results may not generalize to patients in other healthcare systems that have fewer processes and structures to support effective pain management. In addition, many improvements in pain management were implemented subsequent to when these data were collected in 2007. We also used self-reported measures of pain outcomes, which consisted of two single-item survey questions. It should be noted that the use of subjective measures of pain outcomes is consistent with standards of pain treatment, which emphasize the subjective nature of pain and stress the importance of the patient's experience of whether his or her pain is adequately relieved [13]. There is consensus that patients' satisfaction with care is an important measure of healthcare quality, and evidence that patient satisfaction is associated with important outcomes such as health status, health-related quality of life, and medication adherence [38-40]. However, future studies should use more comprehensive measures of pain outcomes, such as those recommended by the Initiative on Methods, Measurement, and Pain Assessment in Clinical Trials (IMMPACT) [29]. A related limitation is our use of a single pain intensity score to stratify the sample rather than use of multiple pain scores or a multidimensional measure of pain. Another potential limitation is that we restricted our sample to patients who did not have an opioid prescription during the 3 mo prior to their Pain Diagnosis index visit. We made this decision to ensure that the opioid prescription was for treatment of that particular chronic pain episode rather than for some other indication. Nonetheless, it is possible that this requirement (that people with pain have an opioid-free period) could limit the generalizability of these conclusions. Additionally, because our definition of opioid use included all patients who received opioid prescriptions any time during the period between the Pain Diagnosis index visit and the SHEP index visit, regardless of duration of prescription or indication, some patients might not have been taking an opioid at the time they had their pain intensity assessed. As a result, our conclusions should be interpreted with caution.

It is also unclear why the association between pain interference and opioid use was stronger among patients with lower pain intensity ratings. While opioids may reduce pain, there is also evidence that they can impair function $[15,41]$. It is possible that patients with lower pain intensity on opioids experienced greater pain relief at the cost of poorer functioning. Another possible explanation is that opioids may have analgesic benefits without improving functioning or reducing pain interference. This might be particularly true for patients who received opioids short-term for acute pain or for temporary exacerbations of chronic pain (i.e., "pain flares") without improving their overall perceptions of functioning or pain interference at the time the SHEP was completed. Future research is required to address this question, which cannot be answered by our study design, as it precludes the ability to draw causal inferences about the effect of opioid prescription on pain outcomes. Patients who received opioids may also have had worse disease severity or prognosis, and this underlying disease rather than opioids (or in conjunction with the opioids) may be contributing to the outcomes assessed. We also are not certain why perceived effectiveness was lower among individuals with mild chronic pain than those with moderate pain. It is possible that pain may be less of a clinical concern among those with lower levels of pain and, therefore, may not be addressed as much by their providers. Consequently, such patients may perceive their pain care to be less effective relative to those with greater 
pain, whose providers may be doing more to address their pain. Future research is needed to address this novel finding. We are also unsure why so many patients received pain intensity ratings of 0 at the clinic visit in which they were given a pain diagnosis. One possibility is that patients were not asked about their pain, but the healthcare professional entered a 0 anyway. Other possibilities are that some disorders that might be presumed to be painful may not be persistently painful (e.g., osteoarthritis) or that pain may be absent when the patient is asked while seated comfortably when other vitals are being taken (e.g., in the case of low back pain or other degenerative disorders).

Several implications for research, policy, and practice flow from this work. First, randomized controlled trials that include a sufficient number of black patients are clearly needed to fill literature gaps about the appropriateness of opioids for chronic noncancer pain. Moreover, the high prevalence of black and white patients who reported substantial pain interference and who perceived their pain treatment as ineffective points to the need to improve the quality of chronic pain treatment available in primary care, where the majority of pain treatment in the VA (and the United States) occurs. Unfortunately, studies conducted in various settings, including the VA, have shown that primary care providers find chronic pain patients to be frustrating and difficult to treat and do not feel adequately prepared to provide care for them [4243]. The growing movement toward "patient-centered medical homes," which are based on principles of accessibility, continuity, and care coordination, provides an opportunity for more effective and equitable chronic pain care $[3,44]$. However, because these models center on the role of primary care providers, it is critical that these providers have training in chronic pain treatment overall and in providing equitable care [3]. Such training should also ensure that providers are aware of nonopioid-based treatments for chronic pain and be familiar with the biopsychosocial model of chronic pain that acknowledges the role of psychological and environmental factors in pain [45]. One promising approach is the VA's Stepped Care Model of Pain Management, in which pain is managed by primary care providers, with support from mental health and specialty services as needed, and which is explicitly designed to promote equitable access to care [46]. A recent evaluation of this program has documented a reduction in referrals to pain medicine specialists, signifying primary care providers' greater confidence in treating chronic pain, as well as a reduction in the proportion of patients receiving high-dose opioids and an increase in referrals to physical therapy and chiropractic care [47]. Although more research is needed, this program and other collaborative care approaches to pain management [48] point to the utility of this approach for improving the quality and equity of treatment for chronic pain.

\section{CONCLUSIONS}

In our retrospective cohort study examining VA primary care patients with a chronic noncancer pain diagnosis, receipt of an opioid prescription was associated with greater pain interference and was not associated with perceived treatment effectiveness for most patients. Findings raise questions about benefits of opioids for musculoskeletal pain and point to the need for alternative treatments for addressing chronic noncancer pain.

\section{ACKNOWLEDGMENTS}

\section{Author Contributions:}

Development of study concept and design: D. J. Burgess (lead), M. J. Bair, R. D. Kerns, D. M. Higgins, M. M. Farmer, M. R. Partin, D. B. Nelson.

Interpretation of data: D. J. Burgess, M. J. Bair, R. D. Kerns, D. M. Higgins, M. M. Farmer, M. R. Partin, A. A. Gravely, D. B. Nelson. Responsible for integrity of data and accuracy of data analysis: D. B. Nelson, A. A. Gravely.

Data analysis: D. B. Nelson (lead), A. A. Gravely.

Drafting of manuscript: D. J. Burgess.

Revision of manuscript for important intellectual content:

M. J. Bair, R. D. Kerns, D. M. Higgins, M. M. Farmer,

M. R. Partin, A. A. Gravely, D. B. Nelson.

Approval of final version to be published: D. J. Burgess, M. J. Bair, R. D. Kerns, D. M. Higgins, M. M. Farmer, M. R. Partin,

A. A. Gravely, D. B. Nelson.

Financial Disclosures: The authors have declared that no competing interests exist.

Funding/Support: This material was based on work supported by three awards from VA Health Services Research and Development Service (HSR\&D): investigator initiated research IIR 07-071

(D.J.B.), VA HSR\&D Research Career Scientist award RCS 10-185

(M.R.P.), and Merit Review Entry Program award MRP 04-412-1 (D.J.B.).

Institutional Review: This study was approved by the institutional review board of the Minneapolis VA Health Care System.

Participant Follow-up: The authors have no plans to notify the study subjects of the publication of this article because of a lack of contact information. 


\section{REFERENCES}

1. Meghani SH, Byun E, Gallagher RM. Time to take stock: A meta-analysis and systematic review of analgesic treatment disparities for pain in the United States. Pain Med. 2012;13(2):150-74. [PMID:22239747] http://dx.doi.org/10.1111/j.1526-4637.2011.01310.x

2. Anderson KO, Green CR, Payne R. Racial and ethnic disparities in pain: Causes and consequences of unequal care. J Pain. 2009;10(12):1187-1204. [PMID:19944378] http://dx.doi.org/10.1016/j.jpain.2009.10.002

3. Meghani SH, Polomano RC, Tait RC, Vallerand AH, Anderson KO, Gallagher RM. Advancing a national agenda to eliminate disparities in pain care: Directions for health policy, education, practice, and research. Pain Med. 2012;13(1):5-28. [PMID:22142450] http://dx.doi.org/10.1111/j.1526-4637.2011.01289.x

4. Shavers VL, Bakos A, Sheppard VB. Race, ethnicity, and pain among the U.S. adult population. J Health Care Poor Underserved. 2010;21(1):177-220. [PMID:20173263] http://dx.doi.org/10.1353/hpu.0.0255

5. Portenoy RK, Ugarte C, Fuller I, Haas G. Population-based survey of pain in the United States: Differences among white, African American, and Hispanic subjects. J Pain. 2004;5(6):317-28. [PMID:15336636] http://dx.doi.org/10.1016/j.jpain.2004.05.005

6. Reyes-Gibby CC, Aday LA, Todd KH, Cleeland CS, Anderson KO. Pain in aging community-dwelling adults in the United States: non-Hispanic whites, non-Hispanic blacks, and Hispanics. J Pain. 2007;8(1):75-84. [PMID:16949874]

http://dx.doi.org/10.1016/j.jpain.2006.06.002

7. Meghani SH, Cho E. Self-reported pain and utilization of pain treatment between minorities and nonminorities in the United States. Public Health Nurs. 2009;26(4):307-16. [PMID:19573209] http://dx.doi.org/10.1111/j.1525-1446.2009.00785.x

8. Allen KD, Oddone EZ, Coffman CJ, Keefe FJ, Lindquist $\mathrm{JH}$, Bosworth HB. Racial differences in osteoarthritis pain and function: Potential explanatory factors. Osteoarthritis Cartilage. 2010;18(2):160-67. [PMID:19825498] http://dx.doi.org/10.1016/j.joca.2009.09.010

9. Ruehlman LS, Karoly P, Newton C. Comparing the experiential and psychosocial dimensions of chronic pain in African Americans and Caucasians: Findings from a national community sample. Pain Med. 2005;6(1):49-60. [PMID:15669950] http://dx.doi.org/10.1111/j.1526-4637.2005.05002.x

10. McCracken LM, Matthews AK, Tang TS, Cuba SL. A comparison of blacks and whites seeking treatment for chronic pain. Clin J Pain. 2001;17(3):249-55.

\section{[PMID:11587117]}

http://dx.doi.org/10.1097/00002508-200109000-00011

11. Burgess DJ, Grill J, Noorbaloochi S, Griffin JM, Ricards J, van Ryn M, Partin MR. The effect of perceived racial discrimination on bodily pain among older African American men. Pain Med. 2009;10(8):1341-52. [PMID:20021596]

12. Edwards RR. The association of perceived discrimination with low back pain. J Behav Med. 2008;31(5):379-89. [PMID:18581224] http://dx.doi.org/10.1007/s10865-008-9160-9

13. Institute of Medicine. Relieving pain in America: A blueprint for transforming prevention, care, education and research. Washington (DC): The National Academies Press; 2011.

14. Eriksen J, Sjøgren P, Bruera E, Ekholm O, Rasmussen NK. Critical issues on opioids in chronic non-cancer pain: An epidemiological study. Pain. 2006;125(1-2):172-79. [PMID:16842922] http://dx.doi.org/10.1016/j.pain.2006.06.009

15. Sjøgren P, Grønbæk M, Peuckmann V, Ekholm O. A population-based cohort study on chronic pain: The role of opioids. Clin J Pain. 2010;26(9):763-69. [PMID:20842015] http://dx.doi.org/10.1097/AJP.0b013e3181f15daf

16. Paulozzi LJ, Budnitz DS, Xi Y. Increasing deaths from opioid analgesics in the United States. Pharmacoepidemiol Drug Saf. 2006;15(9):618-27. [PMID:16862602] http://dx.doi.org/10.1002/pds.1276

17. Warner M, Chen L, Makuc D. Increase in fatal poisonings involving opioid analgesics in the United States, 19992006. Hyattsville (MD): National Center for Health Statistics; 2009.

18. Centers for Disease Control and Prevention (CDC). Overdose deaths involving prescription opioids among Medicaid enrollees-Washington, 2004-2007. MMWR Morb Mortal Wkly Rep. 2009;58(42):1171-75. [PMID:19875978]

19. Burgess DJ, Nelson DB, Gravely AA, Bair MJ, Kerns RD, Higgins DM, van Ryn M, Farmer M, Partin MR. Racial differences in prescription of opioid analgesics for chronic noncancer pain in a national sample of veterans. J Pain. 2014;15(4):447-55. [PMID:24440840] http://dx.doi.org/10.1016/j.jpain.2013.12.010

20. Dobscha SK, Soleck GD, Dickinson KC, Burgess DJ, Lasarev MR, Lee ES, McFarland BH. Associations between race and ethnicity and treatment for chronic pain in the VA. J Pain. 2009;10(10):1078-87. [PMID:19800567] http://dx.doi.org/10.1016/j.jpain.2009.04.018

21. Lacey RJ, Belcher J, Croft PR. Does life course socioeconomic position influence chronic disabling pain in older adults? A general population study. Eur J Public Health. 2013;23(4):534-40. [PMID:22874735] http://dx.doi.org/10.1093/eurpub/cks056 
22. Reme SE, Dennerlein JT, Hashimoto D, Sorensen G. Musculoskeletal pain and psychological distress in hospital patient care workers. J Occup Rehabil. 2012;22(4):503-10. PMID:9431328] http://dx.doi.org/10.1007/s10926-012-9361-5

23. Higgins DM, Kerns RD, Brandt CA, Haskell SG, Bathulapalli H, Gilliam W, Goulet JL. Persistent pain and comorbidity among Operation Enduring Freedom/Operation Iraqi Freedom/Operation New Dawn veterans. Pain Med. 2014;15(5):782-90. [PMID: 24548466]

24. Tan G, Jensen MP, Thornby JI, Anderson KO. Are patient ratings of chronic pain services related to treatment outcome? J Rehabil Res Dev. 2006;43(4):451-60.

[PMID:17123185]

http://dx.doi.org/10.1682/JRRD.2004.10.0128

25. Ratanawongsa N, Bhandari VK, Handley M, Rundall T, Hammer H, Schillinger D. Primary care provider perceptions of the effectiveness of two self-management support programs for vulnerable patients with diabetes. J Diabetes Sci Technol. 2012;6(1):116-24. [PMID:22401329] http://dx.doi.org/10.1177/193229681200600114

26. Sullivan MD, Edlund MJ, Fan MY, Devries A, Brennan Braden J, Martin BC. Trends in use of opioids for non-cancer pain conditions 2000-2005 in commercial and Medicaid insurance plans: the TROUP study. Pain. 2008;138(2): 440-49 [PMID:18547726]

27. Elixhauser A, Steiner C, Harris DR, Coffey RM. Comorbidity measures for use with administrative data. Med Care. 1998;36(1):8-27. [PMID:9431328]

28. Cleeland CS, Reyes-Gibby CC, Schall M, Nolan K, Paice J, Rosenberg JM, Tollett JH, Kerns RD. Rapid improvement in pain management: The Veterans Health Administration and the Institute for Healthcare Improvement Collaborative. Clin J Pain. 2003;19(5):298-305.

[PMID:12966255] http://dx.doi.org/10.1097/00002508-200309000-00003

29. Dworkin RH, Turk DC, Farrar JT, Haythornthwaite JA, Jensen MP, Katz NP, Kerns RD, Stucki G, Allen RR, Bellamy N, Carr DB, Chandler J, Cowan P, Dionne R, Galer BS, Hertz S, Jadad AR, Kramer LD, Manning DC, Martin S, McCormick CG, McDermott MP, McGrath P, Quessy S, Rappaport BA, Robbins W, Robinson JP, Rothman M, Royal MA, Simon L, Stauffer JW, Stein W, Tollett J, Wernicke J, Witter J; IMMPACT. Core outcome measures for chronic pain clinical trials: IMMPACT recommendations. Pain. 2005;113(1-2):9-19. [PMID:15621359]

30. Little RJ, Rubin DB. Statistical analysis with missing data. 2nd ed. Hoboken (NJ): Wiley Interscience; 2002.

31. Gatchel RJ, Peng YB, Peters ML, Fuchs PN, Turk DC. The biopsychosocial approach to chronic pain: Scientific advances and future directions. Psychol Bull. 2007;133(4):
581-624. [PMID:17592957]

http://dx.doi.org/10.1037/0033-2909.133.4.581

32. King AC, Castro C, Wilcox S, Eyler AA, Sallis JF, Brownson RC. Personal and environmental factors associated with physical inactivity among different racial-ethnic groups of U.S. middle-aged and older-aged women. Health Psychol. 2000;19(4):354-64. [PMID:10907654]

http://dx.doi.org/10.1037/0278-6133.19.4.354

33. Kelly CM, Schootman M, Baker EA, Barnidge EK, Lemes A. The association of sidewalk walkability and physical disorder with area-level race and poverty. J Epidemiol Community Health. 2007;61(11):978-83.

[PMID:17933956]

http://dx.doi.org/10.1136/jech.2006.054775

34. Golightly YM, Dominick KL. Racial variations in selfreported osteoarthritis symptom severity among veterans. Aging Clin Exp Res. 2005;17(4):264-69.

[PMID:16285190] http://dx.doi.org/10.1007/BF03324608

35. Jones A, Kwoh CK, Kelley ME, Ibrahim SA. Racial disparity in knee arthroplasty utilization in the Veterans Health administration. Arthritis Rheum. 2005;53(6):979-81.

[PMID:16342110]

http://dx.doi.org/10.1002/art.21596

36. Dominick KL, Dudley TK, Grambow SC, Oddone EZ, Bosworth HB. Racial differences in health care utilization among patients with osteoarthritis. J Rheumatol. 2003; 30(10):2201-6. [PMID:14528518]

37. Dominick KL, Bosworth HB, Dudley TK, Waters SJ, Campbell LC, Keefe FJ. Patterns of opioid analgesic prescription among patients with osteoarthritis. J Pain Palliat Care Pharmacother. 2004;18(1):31-46. [PMID:15148007] http://dx.doi.org/10.1080/J354v18n01_03

38. Ren XS, Kazis L, Lee A, Rogers W, Pendergrass S. Health status and satisfaction with health care: A longitudinal study among patients served by the Veterans Health Administration. Am J Med Qual. 2001;16(5):166-73. [PMID:11591016] http://dx.doi.org/10.1177/106286060101600504

39. Renzi C, Tabolli S, Picardi A, Abeni D, Puddu P, Braga M. Effects of patient satisfaction with care on health-related quality of life: A prospective study. J Eur Acad Dermatol Venereol. 2005;19(6):712-18. [PMID:16268876] http://dx.doi.org/10.1111/j.1468-3083.2005.01301.x

40. Hirsh AT, Atchison JW, Berger JJ, Waxenberg LB, Lafayette-Lucey A, Bulcourf BB, Robinson ME. Patient satisfaction with treatment for chronic pain: Predictors and relationship to compliance. Clin J Pain. 2005;21(4):30210. [PMID:15951647]

http://dx.doi.org/10.1097/01.ajp.0000113057.92184.90

41. Bostick GP, Toth C, Carr EC, Stitt LW, Morley-Forster P, Clark AJ, Lynch M, Gordon A, Nathan H, Smyth C, Ware 
MA, Moulin DE. Physical functioning and opioid use in patients with neuropathic pain. Pain Med. 2015;16(7): 1361-68. [PMID:25645728]

http://dx.doi.org/10.1111/pme.12702

42. Dobscha SK, Corson K, Flores JA, Tansill EC, Gerrity MS. Veterans affairs primary care clinicians' attitudes toward chronic pain and correlates of opioid prescribing rates. Pain Med. 2008;9(5):564-71. [PMID:18777608] http://dx.doi.org/10.1111/j.1526-4637.2007.00330.x

43. Upshur CC, Luckmann RS, Savageau JA. Primary care provider concerns about management of chronic pain in community clinic populations. J Gen Intern Med. 2006; 21(6):652-55. [PMID:16808752] http://dx.doi.org/10.1111/j.1525-1497.2006.00412.x

44. Gallagher RM. The pain medicine and primary care community rehabilitation model: Monitored care for pain disorders in multiple settings. Clin J Pain. 1999;15(1):1-3. [PMID:10206560] http://dx.doi.org/10.1097/00002508-199903000-00001

45. Kerns RD, Sellinger J, Goodin BR. Psychological treatment of chronic pain. Annu Rev Clin Psychol. 2011;7:41134. [PMID:21128783] http://dx.doi.org/10.1146/annurev-clinpsy-090310-120430

46. Rosenberger PH, Philip EJ, Lee A, Kerns RD. The VHA's National Pain Management Strategy: Implementing the Stepped Care Model. Fed Pract. 2011;28(8):39-42.

47. Dorflinger L, Moore B, Goulet J, Becker W, Heapy AA, Sellinger JJ, Kerns RD. A partnered approach to opioid management, guideline concordant care and the stepped care model of pain management. J Gen Intern Med.
2014;29(Suppl 4):870-76. [PMID:25355083]

http://dx.doi.org/10.1007/s11606-014-3019-2

48. Dobscha SK, Corson K, Perrin NA, Hanson GC, Leibowitz RQ, Doak MN, Dickinson KC, Sullivan MD, Gerrity MS. Collaborative care for chronic pain in primary care: A cluster randomized trial. JAMA. 2009;301(12):1242-52. [PMID:19318652] http://dx.doi.org/10.1001/jama.2009.377

Submitted for publication October 22, 2014. Accepted in revised form September 11, 2015.

This article and any supplementary material should be cited as follows:

Burgess DJ, Gravely AA, Nelson DB, Bair MJ, Kerns RD, Higgins DM, Farmer MM, Partin MR. Association between pain outcomes and race and opioid treatment: Retrospective cohort study of Veterans. J Rehabil Res Dev. 2016;53(1):13-24.

http://dx.doi.org/10.1682/JRRD.2014.10.0252

ORCID: Diana J. Burgess, PhD: 0000-0003-1139-7739; Robert D. Kerns, PhD: 0000-0001-7609-2771; Diana M. Higgins, PhD: 0000-0002-6885-266X

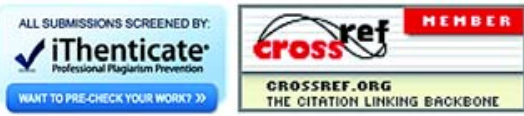

